\section{Research Square}

\title{
Risk factors for the recurrence of relapsing polychondritis
}

\section{Tsuneyasu Yoshida}

Kyoto University: Kyoto Daigaku https://orcid.org/0000-0003-3114-8959

Hajime Yoshifuji ( $\square$ yossii@kuhp.kyoto-u.ac.jp )

Kyoto University: Kyoto Daigaku https://orcid.org/0000-0001-7082-4900

\section{Mirei Shirakashi}

Kyoto University: Kyoto Daigaku

\section{Akiyoshi Nakakura}

Kyoto University: Kyoto Daigaku

Kosaku Murakami

Kyoto University: Kyoto Daigaku

\section{Koji Kitagori}

Kyoto University: Kyoto Daigaku

\section{Shuji Akizuki}

Kyoto University: Kyoto Daigaku

\section{Ran Nakashima}

Kyoto University: Kyoto Daigaku

\section{Koichiro Ohmura}

Kyoto University: Kyoto Daigaku

\section{Akio Morinobu}

Kyoto University: Kyoto Daigaku

\section{Research article}

Keywords: Relapsing polychondritis, recurrence, glucocorticoid, immunosuppressant, biologics

Posted Date: August 19th, 2021

DOl: https://doi.org/10.21203/rs.3.rs-808558/v1

License: (1) (1) This work is licensed under a Creative Commons Attribution 4.0 International License. Read Full License 


\section{Abstract \\ Background}

Although the survival rates of relapsing polychondritis (RP) have increased remarkably, the high recurrence rate remains a significant concern for physicians and patients. This retrospective study aimed to investigate the risk factors for RP recurrence.

\section{Methods}

Patients with RP who presented to Kyoto University Hospital from January 2000 to March 2020 and fulfilled Damiani's classification criteria were included. Patients were classified into recurrence and nonrecurrence groups. Risk factors for RP recurrence were analysed using a Cox proportional hazards model, and Kaplan-Meier survival curves were drawn.

\section{Results}

Thirty-four patients were included. Twenty-five patients (74\%) experienced 64 recurrences (mean: 2.56 recurrences per patients). The median duration before the first recurrence was 202 [55 - 382] days. The median prednisolone dose at the initial recurrence was 10 [5-12.75] mg/day. Tracheal involvement was significantly more frequent in the recurrence group at the initial presentation $(44.0 \%$ vs. $0.0 \%, p=0.0172)$ than in the non-recurrence group, and pre-treatment C-reactive protein levels were significantly high (4.7 vs $1.15 \mathrm{mg} / \mathrm{dL}, \mathrm{p}=0.0024)$. The Cox proportional hazards model analysis revealed that tracheal involvement (HR 4.266 [1.535 - 13.838], $p=0.0048)$, pre-treatment C-reactive protein level (HR 1.166 [1.040 - 1.308], $p$ $=0.0085)$, and initial prednisolone monotherapy (HR 4.443 [1.515 - 16.267], $p=0.0056)$ may be associated with recurrence. The median time before the initial recurrence was significantly longer in patients who received combination therapy with prednisolone and immunosuppressants or biologics (400 vs 70 days, $p=0.0015)$.

\section{Conclusions}

Tracheal involvement, pre-treatment C-reactive protein level, and initial prednisolone monotherapy were risk factors for recurrence in patients with RP. Initial combination therapy with prednisolone and immunosuppressants may delay recurrence.

\section{Background}

Relapsing polychondritis is a rare disease that causes inflammation of the chondrocytes of the ear, nose, and trachea, and it can affect any organ of the body (1). Although corticosteroid therapy is the mainstream treatment for RP, immunosuppressive drugs, such as conventional synthetic DMARDs $(2,3)$, 
biologics (4), and JAK inhibitors (5), have been used empirically in cases of treatment resistance or severe cases. The 5-year and 10-year survival rates of RP were $74 \%$ and $55 \%$, respectively, in 1986, whereas higher rates (95\% and 91\%, respectively) were reported in $2016(6,7)$. This improvement is considered to be due to the early detection of RP, the availability of new immunosuppressive drugs, and intensified treatment by individual physicians (7).

However, achieving remission for RP remains challenging. A French study showed that only $19 \%$ of the patients achieved complete treatment response in the first 6 months, despite the use of biologics (4). Furthermore, a recent study showed that most patients with RP have persistent disease activity, despite treatment (8). In addition, the recurrence of symptoms that require intensive treatment is often encountered in clinical practice and poses a considerable concern for physicians and patients. Repeat recurrences of RP can lead to irreversible organ damage. Particularly, in tracheal chondritis, chronic repetitive inflammation can cause irreversible destruction and fibrosis of the trachea, resulting in a high risk of mortality $(9,10)$. Therefore, it is crucial to understand the risk factors for RP recurrence, for preventive purposes. However, due to the rarity of this disease, only few reports are available in the literature.

We retrospectively analysed the records of 34 patients with RP to determine the risk factors associated with RP recurrence.

\section{Methods}

\section{Patients}

Patients who presented with RP at Kyoto University Hospital from January 2000 to March 2020 and fulfilled Damiani's classification criteria (11) were included in this study. Patients who were followed up for less than 1 year or those who had a history of glucocorticoid use for the treatment of other diseases (i.e., concomitant autoimmune diseases, such as systemic lupus erythematosus, mixed connective tissue disease, and dermatomyositis) before RP treatment were excluded. Auricular, nasal, and tracheal cartilage involvement were diagnosed based on physical examination, imaging (CT and PET-CT), or pathohistological findings. RP relapse was defined as 1) worsening or newly developed symptoms related to RP, which were detected by physical examination or imaging studies and had led to the intensification of treatment or 2) the elevation of inflammatory biomarkers (C-reactive protein [CRP] and erythrocyte sedimentation rate [ESR]) from basal levels, which was considered to be due to the activity of RP and had led to the intensification of treatment.

\section{Evaluation of clinical laboratory parameters}

Blood tests included tests for CRP level (normal range $\leq 0.3 \mathrm{mg} / \mathrm{dL}$ ), erythrocyte sedimentation rate ( $\leq$ $10 / \mathrm{h}$ ), ferritin level (<280 ng/mL), IgG level ( $820-1740 \mathrm{mg} / \mathrm{dL})$, and white blood cell count, which were measured by standard methods. Anti-type II collagen antibody was measured via the ELISA technique (Mayo Clinic Laboratories, cut-off $>25 \mathrm{EU} / \mathrm{mL}$ ). 


\section{Statistical analysis}

Chi-square test and Wilcoxon's rank-sum test were used to analyse categorical and numerical variables, respectively. Survival curves for treatment were drawn via the Kaplan-Meier method. Univariate analysis was performed to explore risk factors for RP relapse. Hazard ratios (HRs) and $95 \%$ confidence intervals (Cls) were estimated using the Cox proportional hazards model. If no relapse was observed for more than a year, the data was time-censored in the first year. Statistical analyses were performed using JMP version 14 and SAS version 9.4 (SAS Institute Inc., Cary, NC, USA). A p-value $<0.05$ was considered statistically significant.

\section{Results}

\section{Patient characteristics}

Thirty-four patients with RP were selected after exclusions (Fig. 1). The clinical characteristics of the 34 patients are shown in Table 1 (left column). There were 17 female patients (50.0\%), the median age was 49 [40 - 67] years, and the median disease duration was 5.0 [2.5 - 6.8] years. Two patients (5.9\%) had Behçet's disease and two other patients (5.9\%) had malignancies (gastric cancer and myelodysplastic syndromes). The most common initial symptom was auricular chondritis (67.6\%), followed by tracheal chondritis (32.4\%) and arthritis (29.4\%). 
Table 1

Patient characteristics

\begin{tabular}{|c|c|c|c|c|}
\hline & Total & $\begin{array}{l}\text { Patients with } \\
\text { recurrence }\end{array}$ & $\begin{array}{l}\text { Patients without } \\
\text { recurrence }\end{array}$ & $\begin{array}{l}\text { P- } \\
\text { value }\end{array}$ \\
\hline Patients, $n$ & 34 & 25 & 9 & \\
\hline Female, n (\%) & $17(50.0)$ & $12(48.0)$ & $5(55.6)$ & 1.0000 \\
\hline Median age at onset, years & $49[40-67]$ & $51[39-66]$ & $65[38-74]$ & 0.3587 \\
\hline Disease duration, years & $\begin{array}{l}5.0[2.5- \\
6.8]\end{array}$ & $5.0[2.0-6.9]$ & $4.5[2.7-6.7]$ & 0.6819 \\
\hline Time until diagnosis, days & $\begin{array}{l}150[86- \\
265]\end{array}$ & $151[83-236]$ & 149 [77-306] & 0.9223 \\
\hline Time until treatment, days & $\begin{array}{l}153[84- \\
270]\end{array}$ & $151[82-245]$ & $175[81-378]$ & 0.4944 \\
\hline Autoimmune disease, n (\%) & $3(8.8)$ & $3(12.0)$ & $0(0.0)$ & 0.5488 \\
\hline Behçet's syndrome & $2(5.9)$ & $2(100.0)$ & $0(0.0)$ & \\
\hline Malignancy, n (\%) & $2(5.9)$ & $2(8.0)$ & $0(0.0)$ & 1.0000 \\
\hline Myelodysplastic syndromes & $1(2.9)$ & $1(100.0)$ & $0(0.0)$ & \\
\hline \multicolumn{5}{|l|}{ Initial symptoms, n (\%) } \\
\hline $\begin{array}{l}\text { Medinan number of initial } \\
\text { symptoms, } \mathrm{n}\end{array}$ & $1[1-2]$ & $1[1-2.5]$ & $1[1-2]$ & 0.385 \\
\hline Auricular involvement & $23(67.6)$ & $15(60.0)$ & $8(88.89)$ & 0.2137 \\
\hline Tracheobronchial involvement & $11(32.4)$ & $11(44.0)$ & $0(0.0)$ & 0.0172 \\
\hline Articular involvement & $10(29.4)$ & $9(36.0)$ & $1(11.1)$ & 0.2250 \\
\hline Nasal involvement & $5(14.7)$ & $3(12.0)$ & $2(22.2)$ & 0.5908 \\
\hline Eye involvement & $4(11.8)$ & $4(16.0)$ & $0(0.0)$ & 0.5536 \\
\hline Vestibulocochlear involvement & $3(8.8)$ & $2(8.0)$ & $1(11.1)$ & 1.0000 \\
\hline Preceding infection & $10(29.4)$ & $8(32.0)$ & $2(22.2)$ & 0.6921 \\
\hline Baseline RPDAI & $25[19-35]$ & $30[19.5-41.5]$ & 23 [13.5-29.5] & 0.0786 \\
\hline
\end{tabular}

Numbers are presented as means (SD) or medians [interquartile range:25\%-75\%]. Chi-square test was used for categorical variables and Wilcoxon's rank-sum test was used for numerical variables. Airway interventions included intubation, tracheostomy, and non-invasive positive pressure ventilation. *Only available data were analysed.

CRP: C-reactive protein, ESR: Erythrocyte sedimentation rate, Hb: Haemoglobin, Plt: Platelet, RPDAl: Relapsing Polychondritis Disease Activity Index. WBC: White blood cell 


\begin{tabular}{|c|c|c|c|c|}
\hline & Total & $\begin{array}{l}\text { Patients with } \\
\text { recurrence }\end{array}$ & $\begin{array}{l}\text { Patients without } \\
\text { recurrence }\end{array}$ & $\begin{array}{l}\mathrm{P}- \\
\text { value }\end{array}$ \\
\hline \multicolumn{5}{|l|}{ Baseline laboratory data } \\
\hline WBC $n=24^{*},(/ \mu l)$ & $\begin{array}{l}7200 \\
{[5870-} \\
8188]\end{array}$ & $\begin{array}{l}7700[6080- \\
8600], n=15\end{array}$ & $\begin{array}{l}7000[5375-8025] \\
n=9\end{array}$ & 0.6798 \\
\hline Neutrophil $n=24^{\star},(/ \mu \mathrm{l})$ & $\begin{array}{l}4774 \\
{[3691-} \\
5971]\end{array}$ & $\begin{array}{l}5605[3806- \\
5986], n=15\end{array}$ & $\begin{array}{l}4613 \text { [3156-5745], } \\
n=9\end{array}$ & 0.4561 \\
\hline Lymphocyte $n=24^{\star},(/ \mu \mathrm{l})$ & $\begin{array}{l}1595 \\
{[1248-} \\
2029]\end{array}$ & $\begin{array}{l}1519[1232- \\
2070], n=15\end{array}$ & $\begin{array}{l}1798[1301-2102] \\
\mathrm{n}=9\end{array}$ & 0.4929 \\
\hline Monocyte $n=24^{\star},(/ \mu \mathrm{l})$ & $\begin{array}{l}435[346- \\
542]\end{array}$ & $\begin{array}{l}468[297-589], n \\
=15\end{array}$ & $\begin{array}{l}378 \text { [272-451], n } \\
=9\end{array}$ & 0.0786 \\
\hline $\mathrm{Hb} \mathrm{n}=25^{\star},(\mathrm{g} / \mathrm{dl})$ & $\begin{array}{l}12.3[10.8- \\
13.8]\end{array}$ & $\begin{array}{l}11.6[10.4-13.9] \\
n=16\end{array}$ & $\begin{array}{l}13.0[11.8-13.9] \\
n=9\end{array}$ & 0.1407 \\
\hline Plt n $=25^{\star},\left(\times 10^{4} / \mu \mathrm{l}\right)$ & $\begin{array}{l}30.3[24.5- \\
38.1]\end{array}$ & $\begin{array}{l}32.5[24.5-46.5] \\
n=16\end{array}$ & $\begin{array}{l}30.3[24.4-30.7] \\
\mathrm{n}=9\end{array}$ & 0.1407 \\
\hline CRP $n=25^{\star},(m g / d l)$ & $\begin{array}{l}3.3[0.72- \\
6.85]\end{array}$ & $\begin{array}{l}4.7[2.60-9.81] \\
\mathrm{n}=16\end{array}$ & $\begin{array}{l}1.15[0.10-3.10] \\
\mathrm{n}=9\end{array}$ & 0.0024 \\
\hline ESR $n=22 *,(m m / h)$ & $\begin{array}{l}70[27- \\
101.5]\end{array}$ & $\begin{array}{l}78[40-107], n= \\
15\end{array}$ & 28 [16-83], n= 7 & 0.0722 \\
\hline $\operatorname{lgG} \mathrm{n}=22^{\star},(\mathrm{mg} / \mathrm{dl})$ & $\begin{array}{l}1455 \\
{[1140-} \\
1836]\end{array}$ & $\begin{array}{l}1704[1249- \\
1982], n=16\end{array}$ & $\begin{array}{l}1159[984-1431] \\
n=6\end{array}$ & 0.0325 \\
\hline $\begin{array}{l}\text { Anti-type II collagen antibody } \\
(+) n=26^{*}, n(\%)\end{array}$ & $13(50.0)$ & $8(47.1), n=17$ & $5(55.6), n=9$ & 1.0000 \\
\hline \multicolumn{5}{|l|}{ Whole treatment } \\
\hline Glucocorticoid, n (\%) & $34(100)$ & $25(100)$ & $9(100)$ & \\
\hline $\begin{array}{l}\text { Initial prednisolone dose, } \mathrm{n}= \\
33^{\star},(\mathrm{mg})\end{array}$ & 30 [15-47.5] & 30 [15-48.75] & $15[10-40]$ & 0.2717 \\
\hline Immunosuppressant, n (\%) & $24(70.6)$ & $23(92.0)$ & $2(22.2)$ & $\begin{array}{l}< \\
0.001\end{array}$ \\
\hline Methotrexate & $20(83.3)$ & $18(72.0)$ & $2(22.2)$ & 0.0168 \\
\hline \multicolumn{5}{|c|}{$\begin{array}{l}\text { Numbers are presented as means (SD) or medians [interquartile range: } 25 \%-75 \% \text { ]. Chi-square test was } \\
\text { used for categorical variables and Wilcoxon's rank-sum test was used for numerical variables. Airway } \\
\text { interventions included intubation, tracheostomy, and non-invasive positive pressure ventilation. *Only } \\
\text { available data were analysed. }\end{array}$} \\
\hline \multicolumn{5}{|c|}{$\begin{array}{l}\text { CRP: C-reactive protein, ESR: Erythrocyte sedimentation rate, Hb: Haemoglobin, Plt: Platelet, RPDAl: } \\
\text { Relapsing Polychondritis Disease Activity Index. WBC: White blood cell }\end{array}$} \\
\hline
\end{tabular}




\begin{tabular}{|c|c|c|c|c|}
\hline & Total & $\begin{array}{l}\text { Patients with } \\
\text { recurrence }\end{array}$ & $\begin{array}{l}\text { Patients without } \\
\text { recurrence }\end{array}$ & $\begin{array}{l}\mathrm{P}- \\
\text { value }\end{array}$ \\
\hline Cyclophosphamide & $8(33.3)$ & $8(32.0)$ & $0(0.0)$ & 0.0770 \\
\hline Azathioprine & $7(29.2)$ & $7(28.0)$ & $0(0.0)$ & 0.1506 \\
\hline Tacrolimus & $6(25.0)$ & $5(20.0)$ & $1(11.1)$ & 1.0000 \\
\hline Cyclosporine A & $2(8.3)$ & $2(8.0)$ & $0(0.0)$ & 1.0000 \\
\hline Biologics, n (\%) & $15(44.1)$ & $12(48.0)$ & $3(33.3)$ & 0.6974 \\
\hline Tocilizumab & $12(80.0)$ & $10(40.0)$ & $2(22.2)$ & 0.4385 \\
\hline Infliximab & $7(46.7)$ & $6(24.0)$ & $1(11.1)$ & 0.6445 \\
\hline Adalimumab & $1(6.7)$ & $1(100.0)$ & $0(0.0)$ & \\
\hline \multicolumn{5}{|l|}{ Outcome } \\
\hline Airway intervention, n (\%) & $6(17.6)$ & $6(24.0)$ & $0(0.0)$ & 0.1622 \\
\hline Death, n (\%) & $2(5.9)$ & $1(4.0)$ & $1(11.1)$ & 0.4652 \\
\hline \multicolumn{5}{|c|}{$\begin{array}{l}\text { Numbers are presented as means (SD) or medians [interquartile range: } 25 \%-75 \%] \text {. Chi-square test was } \\
\text { used for categorical variables and Wilcoxon's rank-sum test was used for numerical variables. Airway } \\
\text { interventions included intubation, tracheostomy, and non-invasive positive pressure ventilation. *Only } \\
\text { available data were analysed. }\end{array}$} \\
\hline \multicolumn{5}{|c|}{$\begin{array}{l}\text { CRP: C-reactive protein, ESR: Erythrocyte sedimentation rate, Hb: Haemoglobin, Plt: Platelet, RPDAl: } \\
\text { Relapsing Polychondritis Disease Activity Index. WBC: White blood cell }\end{array}$} \\
\hline
\end{tabular}

The median relapsing polychondritis disease activity index (RPDAI) score before treatment was 25 [1935]. The median CRP level and ESR before treatment were $3.3[0.7-6.9] \mathrm{mg} / \mathrm{dL}(\mathrm{n}=25)$ and 70 [27 - 102] $\mathrm{mm} / \mathrm{h}(\mathrm{n}=22)$, respectively. Anti-type II collagen antibodies were detected in $50 \%(13 / 26)$ of specimens obtained from the patients. Glucocorticoids (prednisolone) was administered to all patients.

Immunosuppressive drugs, most commonly, methotrexate $(83.3 \%, 20 / 24)$, followed by cyclophosphamide (33.3\%, 8/24), azathioprine $(29.2 \%, 7 / 24)$, and tacrolimus $(25.0 \%, 6 / 24)$, were prescribed to $70.6 \%(24 / 34)$ of all patients. Biologics, most commonly, tocilizumab $(80.0 \%, 12 / 15)$, followed by infliximab $(46.7 \%$, $7 / 15)$, were administered to $44.1 \%(15 / 34)$ of all patients. Six patients $(17.6 \%)$ required airway interventions, such as intubation, tracheostomy, and non-invasive positive pressure ventilation. Two deaths $(5.9 \%)$ were recorded. The causes of death could not be identified, except for old age ( 80 and 81 years).

\section{Characteristics of patients who experienced recurrence}

Of the 34 patients, 25 (74\%) experienced recurrences (64 recurrences; mean: 2.56 recurrences per patient; minimum 1, maximum 9; 0.16 person-year) (Table 2). Eleven recurrences $(11 / 64,17.2 \%)$ were major events, requiring hospitalization. The median age of the patients at the time of initial recurrence was 50 [40 - 67] years, and the median duration before the first recurrence was 202 [55 - 382] days. Six of the 
initial recurrences were major events $(6 / 25,24 \%)$. The median prednisolone dose at the time of initial RP recurrence was 10 [5-12.75] mg/day. The initial symptoms recurred in $68 \%(17 / 25)$ of the cases, and one patient experienced the recurrence of encephalitis.

Table 2

Characteristics of the disease recurrences

Present study

\section{Total recurrence}

Total number of recurred patients, (number)

Total number of recurrences, (times)

Mean number of recurrences, (times/person)

Person-years

Major recurrence, $\mathrm{n}(\%)$

Minor recurrence, $\mathrm{n}(\%)$

Initial recurrence, $\mathrm{n}=\mathbf{2 5}$

Median age at initial recurrence, (years old)

Median days to initial recurrence, (days)

Major recurrence, $\mathrm{n}(\%)$

Minor recurrence, $\mathrm{n}(\%)$

Median PSL doses at initial recurrence, $(\mathrm{mg})$

Symptoms at initial recurrence

Tracheobronchial involvement

Auricular involvement

Nasal involvement

Articular involvement

Eye involvement

Vestibulocochlear involvement

Encephalitis

Concordance of initial symptoms and symptoms at initial recurrence

Numbers are presented as means (SD) or medians [interquartile range:25\%-75\%]. Some patients had several symptoms at the initial recurrence. Major recurrence: required admission. Minor recurrence: did not require admission. PSL: Prednisolone.
25

64

2.56

0.16

$11(17.2)$

$53(82.8)$

51 [40-67]

202 [55-382]

$6(24.0)$

19 (76.0)

10 [5-12.75]

$10(40.0)$

$6(24.0)$

3 (12.0)

3 (12.0)

2 (8.0)

2 (8.0)

1 (4.0)

17 (68.0) 


\section{Risk factors for recurrence}

To investigate the risk factors for recurrence, we divided the entire patient cohort $(n=34)$ into recurrence and non-recurrence groups. There were no significant differences in age, sex, disease duration, or observation period between the two groups before treatment (Table 1, middle and right columns). Although there was no significant difference in the number of symptoms at the initial presentation, occurrence of tracheal lesions at the initial presentation was associated with RP recurrence $(44.0 \% \mathrm{vs} 0 \%$, $\mathrm{p}=0.0172$ ). Pre-treatment RPDAl tended to be higher in the recurrence group than in the non-recurrence group (median 30 vs $23, p=0.0786$ ). Serum IgG levels were also significantly higher in the recurrence group than in the non-recurrence group (median: $1704 \mathrm{vs} 1159 \mathrm{mg} / \mathrm{dL}, \mathrm{p}=0.0325$ ), although serum IgG levels remained within the normal range. Monocyte count tended to be higher in the recurrence group than in the non-recurrence group (median 468 vs $378 / \mu \mathrm{L}, \mathrm{p}=0.0786$ ). Positive results of the anti-type II collagen antibody test were not associated with RP recurrence ( $47.1 \%$ vs $55.6 \%, p=1.0000)$. There were no significant differences in the initial prednisolone dose between the recurrence and non-recurrence groups (30 vs $15 \mathrm{mg}, \mathrm{p}=0.2717$ ). However, immunosuppressive agents (particularly methotrexate) were more commonly used in the recurrence group than in the non-recurrence group ( $72.2 \%$ vs $22.2 \%, p=$ 0.0168). Regarding prognosis, interventions for airway lesions, such as intubation, tracheostomy, and non-invasive positive pressure ventilation use (6 patients), were recorded in the recurrence group alone, although no significant between-group difference was observed $(24.0 \%$ vs $0.0 \%, p=0.1622)$.

We performed a univariate analysis of major risk factors for relapse (Table 3). Pre-treatment CRP level (HR 1.166, 95\% Cl, $1.040-1.308, p=0.0085)$ was found to be a potential risk factor for RP recurrence. Monocyte count (HR 1.04, 95\% Cl, $1.000-1.008, p=0.0690$ ) also tended to be a risk factor, although no significant between-group difference was observed. The hazard ratio for tracheal lesions was 2.666 (95\% $\mathrm{Cl}, 1.014-8.283, \mathrm{p}=0.0466)$. After adjusting for the initial treatment, the hazard ratio raised to 4.266 $(95 \% \mathrm{Cl} 1.535-13.838, p=0.0048)$. 
Table 3

Univariate analysis of risk factors for recurrence

\begin{tabular}{|lll|}
\hline Dependent variables & Recurrence risk & \\
\hline Variables & Univariate models HR $(\mathrm{Cl})$ & P-value \\
\hline Age at diagnosis & $1002(0.978,1.027)$ & 0.8640 \\
\hline Sex & $0.857(0.348,2.111)$ & 0.7373 \\
\hline Time until treatment & $0.998(0.995,1.001)$ & 0.1570 \\
\hline RPDAl & $1.010(0.971,1.050)$ & 0.6305 \\
\hline Tracheobronchial involvement & $2.666(1.014,8.283)$ & 0.0466 \\
\hline Adjusted by initial PSL monotherapy & $4.266(1.535,13.838)$ & 0.0048 \\
\hline Auricular involvement & $0.674(0.264,1.717)$ & 0.4083 \\
\hline CRP & $1.166(1.040,1.308)$ & 0.0085 \\
\hline ESR & $1.009(0.994,1.024)$ & 0.2231 \\
\hline Monocyte & $1.004(1.000,1.008)$ & 0.0690 \\
\hline IgG & $1.000(0.999,1.001)$ & 0.3586 \\
\hline Initial PSL monotherapy & $2.718(0.981,9.565)$ & 0.0547 \\
\hline Adjusted by tracheobronchial involvement & $4.443(1.515,16.267)$ & 0.0056 \\
\hline Initial PSL dose & $1.008(0.986,1.030)$ & 0.4802 \\
\hline CRP: C-reactive protein, ESR: Erythrocyte sedimentation rate, PSL: Prednisolone, RPDAl: Relapsing & \\
\hline Polychondritis Disease Activity Index. & & \\
\hline
\end{tabular}

\section{Efficacy of combination therapy with immunosuppressants}

To investigate the preventive effect of immunosuppressive drugs on relapse, we divided the entire cohort into two groups: PM group and prednisolone combined with immunosuppressants/biologics (PC) group. Table 4 shows the background of patients in each group. The PC group received the following immunosuppressants and biologics: methotrexate (5 patients), intravenous cyclophosphamide (3 patients), azathioprine (1 patient), infliximab (1 patient), and methotrexate, which was changed to tocilizumab (1 patient). There were no differences in age, sex, disease duration, or observation period between the groups. The rate of concomitant use of immunosuppressants was significantly higher when the initial symptom included tracheal involvement $(63.6 \%$ vs $17.4 \%, p=0.0160)$. The dose of prednisolone at the initiation of treatment was not entirely different between the PM and PC groups (28 vs $40 \mathrm{mg}, \mathrm{p}=0.2566$ ). The median prednisolone dose in both groups at relapse was $10 \mathrm{mg}$, and the rate of prednisolone dose reduction before the first relapse was not significantly different between the two 
groups (PM 0.1 vs PC $0.03 \mathrm{mg}, \mathrm{p}=0.2691$ ). The median duration before initial RP recurrence was significantly longer in the PC group (400 vs 70 days, $p=0.0015$ ). 
Table 4

Comparison of prednisolone monotherapy (PM) and prednisolone combined with immunosuppressants/biologics (PC) groups

\begin{tabular}{|c|c|c|c|}
\hline & PM & PC & \multirow[t]{2}{*}{$\begin{array}{l}\mathrm{P}- \\
\text { value }\end{array}$} \\
\hline & $\mathrm{n}=\mathbf{2 3}$ & $\mathrm{n}=11$ & \\
\hline Age at onset, (years) & $52[45-70]$ & $46[30-58]$ & 0.1616 \\
\hline Female, n (\%) & $13(56.5)$ & $4(36.4)$ & 0.4646 \\
\hline Disease duration, (years) & $5.5[2.9-6.8]$ & $4.5[1.8-12.9]$ & 0.6720 \\
\hline Time until diagnosis, (days) & $151[78-270]$ & $105[91-235]$ & 0.8684 \\
\hline Time until treatment, (days) & $151[78-270]$ & $156[99-467]$ & 0.6586 \\
\hline \multicolumn{4}{|l|}{ Initial symptoms, n (\%) } \\
\hline Auricular & $18(78.3)$ & $5(45.5)$ & 0.1143 \\
\hline Tracheobronchial & $4(17.4)$ & $7(63.6)$ & 0.0160 \\
\hline RPDAl & $23[15-41]$ & 33 [22-35] & 0.2851 \\
\hline WBC, $(/ \mu \mathrm{l})$ & $\begin{array}{l}7000[5500-8200], \\
n=15\end{array}$ & $\begin{array}{l}7710[6325-8375] \\
n=9\end{array}$ & 0.5913 \\
\hline Monocyte, $(/ \mu \mathrm{l})$ & $\begin{array}{l}444[308-596], n= \\
15\end{array}$ & $\begin{array}{l}430[388-471], n= \\
9\end{array}$ & 0.8815 \\
\hline $\mathrm{Hb},(\mathrm{g} / \mathrm{dl})$ & $\begin{array}{l}12.4[10.8-13.9], n= \\
15\end{array}$ & $\begin{array}{l}11.8[10.4-13.8], n \\
=10\end{array}$ & 0.6570 \\
\hline Plt, $(\times 104 / \mu \mathrm{l})$ & $\begin{array}{l}30.1[21.5-32.7], n= \\
15\end{array}$ & $\begin{array}{l}33.9[26.6-49.4], n \\
=10\end{array}$ & 0.0521 \\
\hline $\mathrm{CRP},(\mathrm{mg} / \mathrm{dl})$ & $2.8[0.5-4.7], n=16$ & 4.5 [1.6-8.7], n= 9 & 0.4270 \\
\hline $\mathrm{ESR},(\mathrm{mm} / \mathrm{h})$ & $70[43-104], n=12$ & $55[22-102], n=10$ & 0.5977 \\
\hline $\operatorname{lgG},(\mathrm{mg} / \mathrm{dl})$ & $\begin{array}{l}1432[1229-1709] \\
\mathrm{n}=12\end{array}$ & $\begin{array}{l}1597[984-2020] \\
\mathrm{n}=10\end{array}$ & 0.7416 \\
\hline Initial PSL doses, (mg) & $\begin{array}{l}28[13.8-41.2], n= \\
22\end{array}$ & 40 [15-70], n= 11 & 0.2566 \\
\hline PSL doses at initial recurrence, $(\mathrm{mg})$ & $10[5-14], n=16$ & $10[6.5-12], n=9$ & 0.9319 \\
\hline
\end{tabular}

Numbers are presented as means (SD) or medians [interquartile range:25\%-75\%]. Chi-square test was used for categorical variables and Wilcoxon's rank-sum test was used for numerical variables.

CRP: C-reactive protein, ESR: Erythrocyte sedimentation rate, Hb: Haemoglobin, IS: Immunosuppressant, PC: Prednisolone combined with immunosuppressants/biologics, Plt: platelet, PM: Prednisolone monotherapy, PSL: Prednisolone, RPDAl: Relapsing Polychondritis Disease Activity Index. WBC: White blood cell 


\begin{tabular}{|c|c|c|c|}
\hline & PM & $\mathrm{PC}$ & \multirow{2}{*}{$\begin{array}{l}\text { P- } \\
\text { value }\end{array}$} \\
\hline & $n=23$ & $\mathrm{n}=11$ & \\
\hline $\begin{array}{l}\text { PSL doses reduction until initial recurrence, } \\
\text { ( } \mathrm{mg} / \text { day) }\end{array}$ & $0.1[0.03-0.4], n=15$ & $\begin{array}{l}0.03[0.015-0.2], n= \\
9\end{array}$ & 0.2691 \\
\hline Time until initial recurrence, (days) & $70[26-211]$ & $400[294-1446]$ & 0.0015 \\
\hline \multicolumn{4}{|c|}{$\begin{array}{l}\text { Numbers are presented as means (SD) or medians [interquartile range: } 25 \%-75 \%] \text {. Chi-square test was } \\
\text { used for categorical variables and Wilcoxon's rank-sum test was used for numerical variables. }\end{array}$} \\
\hline \multicolumn{4}{|c|}{$\begin{array}{l}\text { CRP: C-reactive protein, ESR: Erythrocyte sedimentation rate, Hb: Haemoglobin, IS: } \\
\text { Immunosuppressant, PC: Prednisolone combined with immunosuppressants/biologics, Plt: platelet, } \\
\text { PM: Prednisolone monotherapy, PSL: Prednisolone, RPDAl: Relapsing Polychondritis Disease Activity } \\
\text { Index. WBC: White blood cell }\end{array}$} \\
\hline
\end{tabular}

Recurrence-free survival curve from the start of treatment is shown in Fig. 2. The hazard ratio for RP recurrence in the PM group versus the PC group was $2.718(95 \% \mathrm{Cl}, 0.981$ - 9.565, $\mathrm{p}=0.0547)$ (Table 3). After adjusting for the influence of tracheal lesions, the hazard ratio was $4.443(95 \% \mathrm{Cl} 1.515-16.267, \mathrm{p}$ $=0.0056)$ (Table 3$)$.

\section{Discussion}

In this study, we retrospectively assessed 34 patients with RP and investigated risk factors for recurrence, which has not been reported before. The characteristics of the patients in our study are similar to those of patients in previous reports. In this study, the age of onset is lower than that in a study by Oka et al. (12) and higher than that in a study by Dion et al. (7). Additionally, the proportion of women is higher than that in the study by Oka et al. and lower than that in the study by Dion et al. Concerning initial symptoms, the high prevalence of auricular chondritis, followed by tracheal chondritis, is consistent with the findings of previous studies (12). In the present study, only one patient (2.9\%) had concomitant myelodysplastic syndromes, which is comparable to the findings of a study of the Japanese population (2.1\%) by Shimizu et al. (13). It was reported that up to $28 \%$ of western patients with RP had myelodysplastic syndromes (14). We considered that this discrepancy in the prevalence of myelodysplastic syndromes is due to differences in ethnic background. Recently, a somatic mutation of the UBA1 gene, which encodes E1 enzyme related to ubiquitination, was found in RP patients with myelodysplastic syndromes. The condition was named VEXAS syndrome (15). Interestingly, Japanese patients with UBA1 gene mutations also have a high prevalence of myelodysplastic syndromes (16). Further studies are required to investigate the prevalence of the mutation of UBA1 gene in the general population among different ethnic groups.

Death was recorded in only two patients during the study period. Generally, the mortality rate of RP is considered to have improved. McAdam et al. reported in 1976 (17) that the mean survival duration in RP was 4.2 years. In 1986, Michet et al. reported (6) a poor prognosis, with a 5 -year survival rate of $74 \%$ and 
a 10 -year survival rate of $55 \%$. Consistent with a previous study, the present study, which included a median observation period of 4.5 years, revealed a mortality rate of $4.9 \%(2 / 41)(7)$. The two cases of death were caused by senility, which is unrelated to RP. This disparity in the mortality rate may be due to the shorter time interval from RP onset to diagnosis in our cohort (150 days), compared to that of previous studies (2.9 years) (18), and the higher rate of concomitant use of immunosuppressants (39$51 \%$ vs $70 \%$ ) and biologics ( $5.4-15 \%$ vs $40 \%$ ), compared to previous reports $(7,12)$. Despite the reduced mortality rate, the present study highlights a high recurrence rate of RP (74\%). A recent study showed that RP had a more persistent active pattern than a relapsing-remitting pattern (8). However, whether RP assumes a chronic active pattern or a relapsing-remitting pattern may depend on differences in treatment and the rate of therapeutic drug reduction. Moreover, further treatment improvement was considered necessary. We found that the median time before the first relapse was 202 days. The median prednisolone dose at the time of recurrence was $10 \mathrm{mg}$, consistent with an expert's opinion, which suggests that a 5-10 mg maintenance dose of prednisolone is suitable for RP (19). In our analysis, 68\% of the patients had similar symptoms at the initial recurrence, while the symptoms in $32 \%$ of the patients at the time of relapse were different from the initial symptoms. This suggests that various symptoms of RP should be considered at the time of recurrence. One patient had auricular chondritis as the initial symptom but had encephalitis symptoms at the time of RP recurrence. This finding is consistent with those of Shimizu et al.'s (20) cluster analyses, which showed the relationship between auricular chondritis and encephalitis.

In the analysis of the risk of recurrence, tracheal involvement, pre-treatment CRP level, and PM were identified as potential risk factors for recurrence. Tracheal involvement was associated with death in previous studies $(17,21,22)$, and the possible mechanisms include ventilation insufficiency or concomitant infection due to airway narrowing or collapse $(18,23)$. The findings of the present study suggested that tracheal involvement is a risk factor for recurrence, and that repeat recurrences may lead to irreversible structural changes in the bronchi.

Pre-treatment RPDAl score was significantly higher in the recurrence group than in the non-recurrence group, although pre-treatment RPDAI was not a recurrence risk factor in the univariate analysis. The RPDAl is an index of activity that scores symptoms and examination findings in RP, using a scale of 1-24 points (24). A relatively high score of 14 or 24 points is assigned to tracheal chondritis, depending on the presence or absence of acute respiratory failure. The recurrence group had a significantly higher median RPDAl score, which may have been influenced by tracheal involvement. A new assessment scale for assessing disease activity is required.

Pre-treatment CRP levels were also identified as risk factors for recurrence in the present study, although the results differ from those of several previous reports. Consistent with our study, which suggests that high pre-treatment CRP level is a risk factor for recurrence, a case series report indicated that CRP level was elevated at the time of RP recurrence (25). However, in some other reports, more than $10 \%$ of the patients had normal CRP levels at the time of recurrence (9), and CRP level was not related to disease 
activity $(26,27)$. According to these two reports $(26,27)$, CRP level was measured in patients who were receiving treatment, and the treatment have may affected the level of this inflammatory marker.

The present study showed a tendency for increased monocyte count related to the risk of recurrence, although the between-group difference was not significant. Previous reports have shown that cytokines such as MCP-1 and MIP-1 $\beta$, which are involved in the migration and activation of monocytes and macrophages, were elevated in the serum of patients with RP (28), suggesting that the activation of monocytes and macrophages may be associated with relapse.

Finally, patients who underwent PM were at a higher risk of recurrence than those who received the combination therapy. This finding is consistent with those of previous researches on IgG4-related disease (29) and ANCA-related vasculitis (30). The risk ratio for recurrence increased when adjustments were made for the presence of initial airway involvement, suggesting the importance of PC therapy, regardless of the involved organ at RP onset. There were several limitations in the present study. First, it was a single-centre, retrospective cohort study. The choice of the therapeutic agent (PM or PC), treatment dose, and rate of dose reduction was at the discretion of the attending physicians; therefore, there was a lack of uniformity regarding treatment strategies, which could affect relapse. Second, there is no established definition of RP relapse; thus, we developed our own relapse criteria, using the definition of relapse in a past research on IgG4-related disease (31), namely, 1) worsening of symptoms related to the primary disease and 2) intensified treatment by the attending physicians. This could affect the generalisability of our study findings. Finally, the sample size was small due to the rarity of the disease. This may have affected the existence of statistically significant differences. A prospective study with a larger number of patients is required.

\section{Conclusions}

This study analysed factors associated with RP recurrence and showed that tracheal lesions and pretreatment serum CRP levels were risk factors for recurrence. Initial therapy with prednisolone alone within the first year of treatment was also a risk factor for recurrence. Initial combination therapy with prednisolone and immunosuppressants or biologics may delay recurrence.

\section{Abbreviations}

$\mathrm{Cl}$

Confidence intervals

CRP

C-reactive protein

\section{DMARD}

Disease-modifying anti-rheumatic drug

\section{ELISA}

Enzyme-linked immunosorbent assay 
ESR

Erythrocyte sedimentation rate

$\mathrm{Hb}$

Haemoglobin

HR

Hazard ratios

IS

Immunosuppressant

PC

Prednisolone combined with immunosuppressants/biologics

Plt

Platelet,

PM

Prednisolone monotherapy

PSL

Prednisolone

RP

Relapsing polychondritis

RPDAl

Relapsing polychondritis disease activity index

WBC

White blood cell

\section{Declarations}

\section{Ethics approval and consent to participate}

This study was approved by the Ethics Committee of Kyoto University Graduate School and Faculty of Medicine (No. G412, G1006), and the study protocol was performed according to the stipulations of the Declaration of Helsinki.

\section{Consent for publication}

We obtained written informed consent from each participant.

\section{Availability of data and materials}

The datasets used and/or analysed during the current study are available from the corresponding author on reasonable request.

\section{Competing interests}

The authors declare that they have no competing interests. 


\section{Funding}

This research was supported in part by Grants-in-Aid from the Cartilaginous Inflammatory Disease Research Group (Chair: Prof. Noboru Suzuki), the Ministry of Health, Labor and Welfare of Japan.

\section{Authors' contributions}

TS, YH, MS designed the study. TS was responsible for the data collection. TS, AN performed the data analyses. TS drafted the manuscript. All authors contributed to the interpretation of the data and approved the final manuscript.

\section{Acknowledgements}

We would like to thank Ms Sze Ming Law and Editage (www.editage.com) for checking the English of the manuscript.

\section{Authors' information}

Department of Rheumatology and Clinical Immunology, Graduate School of Medicine, Kyoto University, Kyoto, Japan.

Tsuneyasu Yoshida, Hajime Yoshifuji, Mirei Shirakashi, Kosaku Murakami, Koji Kitagori, Shuji Akizuki, Ran Nakashima, Koichiro Ohmura, Akio Morinobu

Department of Biomedical Statistics and Bioinformatics, Kyoto University Graduate School of Medicine, Japan.

Akiyoshi Nakakura

Corresponding author

Hajime Yoshifuji

\section{References}

1. Kingdon J, Roscamp J, Sangle S, D'Cruz D. Relapsing polychondritis: a clinical review for rheumatologists. Rheumatol Oxf Engl. 2018 Sep 1;57(9):1525-32.

2. Rednic S, Damian L, Talarico R, Scirè CA, Tobias A, Costedoat-Chalumeau N, et al. Relapsing polychondritis: state of the art on clinical practice guidelines. RMD Open. 2018;4(Suppl 1):e000788.

3. Borgia F, Giuffrida R, Guarneri F, Cannavò SP. Relapsing Polychondritis: An Updated Review. Biomedicines. 2018 Aug 2;6(3). 
4. Moulis G, Pugnet G, Costedoat-Chalumeau N, Mathian A, Leroux G, Boutémy J, et al. Efficacy and safety of biologics in relapsing polychondritis: a French national multicentre study. Ann Rheum Dis. 2018;77(8):1172-8.

5. Meshkov AD, Novikov PI, Zhilyaev EV, llevsky IDJ, Moiseev SV. Tofacitinib in steroid-dependent relapsing polychondritis. Ann Rheum Dis. 2019 Jul;78(7):e72.

6. Michet CJ, McKenna CH, Luthra HS, O'Fallon WM. Relapsing polychondritis. Survival and predictive role of early disease manifestations. Ann Intern Med. 1986 Jan;104(1):74-8.

7. Dion J, Costedoat-Chalumeau N, Sène D, Cohen-Bittan J, Leroux G, Dion C, et al. Relapsing Polychondritis Can Be Characterized by Three Different Clinical Phenotypes: Analysis of a Recent Series of 142 Patients. Arthritis Rheumatol Hoboken NJ. 2016;68(12):2992-3001.

8. Rose E, Ferrada MA, Quinn KA, Goodspeed W, Arnaud L, Sharma A, et al. Physician Global Assessment as a Disease Activity Measure for Relapsing Polychondritis. Arthritis Care Res. 2021 Feb 5;

9. Mathian A, Miyara M, Cohen-Aubart F, Haroche J, Hie M, Pha M, et al. Relapsing polychondritis: A 2016 update on clinical features, diagnostic tools, treatment and biological drug use. Best Pract Res Clin Rheumatol. 2016;30(2):316-33.

10. Tillie-Leblond I, Wallaert B, Leblond D, Salez F, Perez T, Remy-Jardin M, et al. Respiratory involvement in relapsing polychondritis. Clinical, functional, endoscopic, and radiographic evaluations. Medicine (Baltimore). 1998 May;77(3):168-76.

11. Damiani JM, Levine HL. Relapsing polychondritis-report of ten cases. The Laryngoscope. 1979 Jun;89(6 Pt 1):929-46.

12. Oka H, Yamano Y, Shimizu J, Yudoh K, Suzuki N. A large-scale survey of patients with relapsing polychondritis in Japan. Inflamm Regen. 2014;34(3):149-56.

13. Shimizu J, Oka H, Yamano Y, Yudoh K, Suzuki N. Cutaneous manifestations of patients with relapsing polychondritis: an association with extracutaneous complications. Clin Rheumatol. 2016 Mar;35(3):781-3.

14. Hebbar M, Brouillard M, Wattel E, Decoulx M, Hatron PY, Devulder B, et al. Association of myelodysplastic syndrome and relapsing polychondritis: further evidence. Leukemia. 1995 Apr;9(4):7313.

15. Beck DB, Ferrada MA, Sikora KA, Ombrello AK, Collins JC, Pei W, et al. Somatic Mutations in UBA1 and Severe Adult-Onset Autoinflammatory Disease. N Engl J Med. 2020 Dec;383(27):2628-38.

16. Tsuchida N, Kunishita Y, Uchiyama Y, Kirino Y, Enaka M, Yamaguchi Y, et al. Pathogenic UBA1 variants associated with VEXAS syndrome in Japanese patients with relapsing polychondritis. Ann 
Rheum Dis. 2021 Mar 31;

17. McAdam LP, O'Hanlan MA, Bluestone R, Pearson CM. Relapsing polychondritis: prospective study of 23 patients and a review of the literature. Medicine (Baltimore). 1976 May;55(3):193-215.

18. Trentham DE, Le CH. Relapsing polychondritis. Ann Intern Med. 1998 Jul;129(2):114-22.

19. Rabuzzi DD. Relapsing polychondritis. Arch Otolaryngol Chic III 1960. 1970 Feb;91(2):188-94.

20. Shimizu J, Yamano Y, Yudoh K, Suzuki N. Organ involvement pattern suggests subgroups within relapsing polychondritis: comment on the article by Dion et al. Arthritis Rheumatol Hoboken NJ. 2018;70(1):148-9.

21. Hazra N, Dregan A, Charlton J, Gulliford MC, D'Cruz DP. Incidence and mortality of relapsing polychondritis in the UK: a population-based cohort study. Rheumatol Oxf Engl. 2015 Dec;54(12):21817.

22. Lin D-F, Yang W-Q, Zhang P-P, Lv Q, Jin O, Gu J-R. Clinical and prognostic characteristics of 158 cases of relapsing polychondritis in China and review of the literature. Rheumatol Int. 2016 Jul;36(7):1003-9.

23. Mohsenifar Z, Tashkin DP, Carson SA, Bellamy PE. Pulmonary function in patients with relapsing polychondritis. Chest. 1982 Jun;81(6):711-7.

24. Arnaud L, Devilliers H, Peng SL, Mathian A, Costedoat-Chalumeau N, Buckner J, et al. The Relapsing Polychondritis Disease Activity Index: development of a disease activity score for relapsing polychondritis. Autoimmun Rev. 2012 Dec;12(2):204-9.

25. Badireddi S, Siddiqui MF, Boddu NJ. Respiratory failure secondary to relapsing polychondritis. Respir Care. 2014 Sep;59(9):e140-143.

26. Sato T, Yamano Y, Tomaru U, Shimizu Y, Ando H, Okazaki T, et al. Serum level of soluble triggering receptor expressed on myeloid cells-1 as a biomarker of disease activity in relapsing polychondritis. Mod Rheumatol. 2014 Jan;24(1):129-36.

27. Thaiss WM, Nikolaou K, Spengler W, Spira D, Xenitidis T, Henes J, et al. Imaging diagnosis in relapsing polychondritis and correlation with clinical and serological data. Skeletal Radiol. 2016 Mar;45(3):339-46.

28. Stabler T, Piette J-C, Chevalier X, Marini-Portugal A, Kraus VB. Serum cytokine profiles in relapsing polychondritis suggest monocyte/macrophage activation. Arthritis Rheum. 2004 Nov;50(11):3663-7.

29. Wang Y, Zhao Z, Gao D, Wang H, Liao S, Dong C, et al. Additive effect of leflunomide and glucocorticoids compared with glucocorticoids monotherapy in preventing relapse of IgG4-related 
disease: A randomized clinical trial. Semin Arthritis Rheum. 2020 Dec;50(6):1513-20.

30. Charles P, Perrodeau É, Samson M, Bonnotte B, Néel A, Agard C, et al. Long-Term Rituximab Use to Maintain Remission of Antineutrophil Cytoplasmic Antibody-Associated Vasculitis: A Randomized Trial. Ann Intern Med. 2020 Aug 4;173(3):179-87.

31. Shirakashi M, Yoshifuji H, Kodama $Y$, Chiba T, Yamamoto $M$, Takahashi $H$, et al. Factors in glucocorticoid regimens associated with treatment response and relapses of IgG4-related disease: a multicentre study. Sci Rep. 2018 Jul 6;8(1):10262.

Figures

\section{6 cases}

\section{Follow-up $<1$ year 1 case}

\section{Preceding GC 4 cases}

\section{Without information of initial recurrence 7 cases}

\section{4 cases}


Flow chart of patient selection. Forty-six patients with RP were selected from medical records. We excluded 4 patients who received follow-up for less than 1 year, 1 patient who previously received glucocorticoids for the treatment of other diseases, and 7 patients with missing data. Finally, univariate analysis was performed with the data of 34 patients.

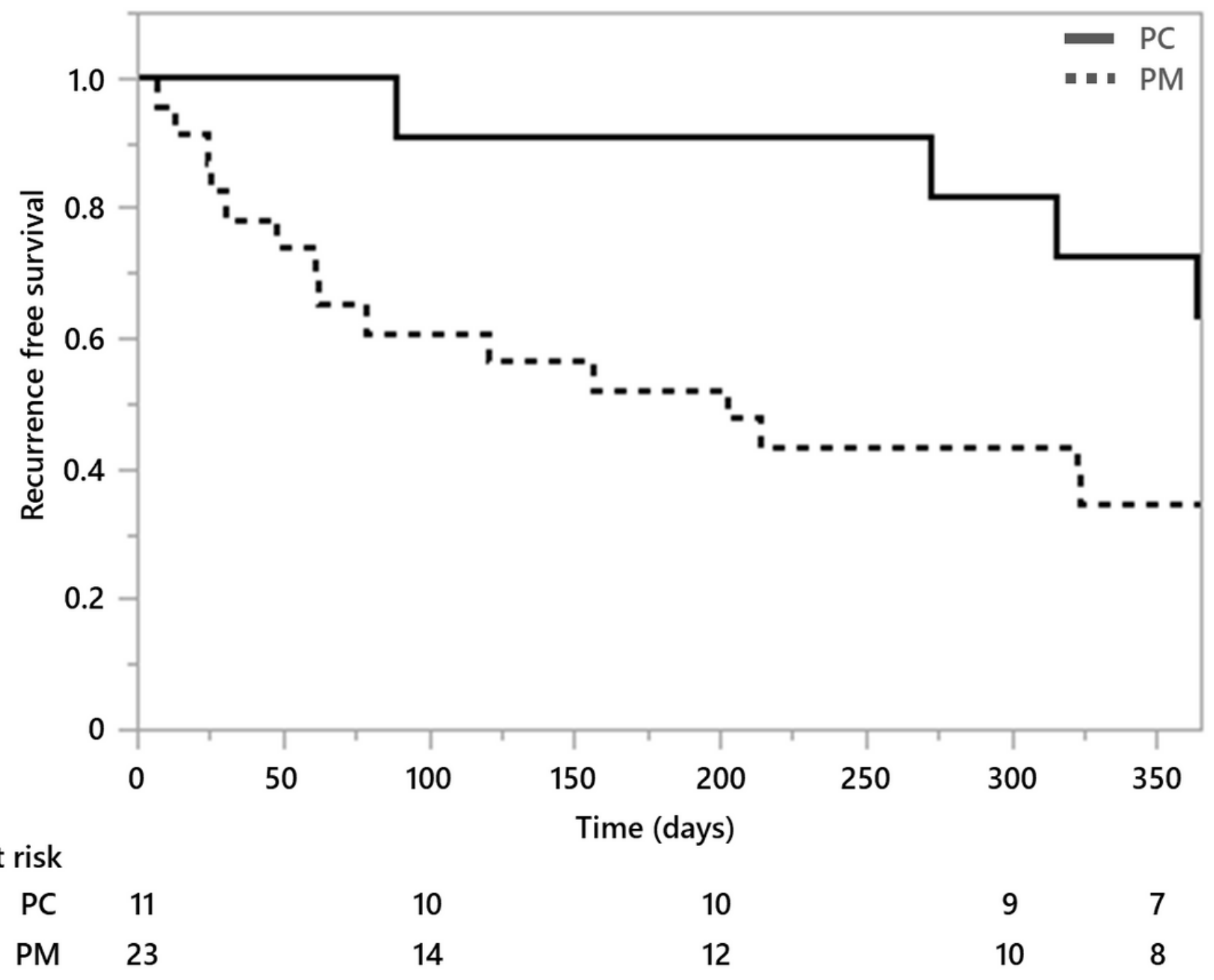

Figure 2

Recurrence-free survival curve of the prednisolone monotherapy (PM) and prednisolone combined with immunosuppressants/biologics (PC) groups. One-year relapse-free survival curves for patients who received prednisolone monotherapy as the initial therapy and for patients who received a combination of prednisolone and immunosuppressants. Wilcoxon test $p=0.0372$ (Log rank test $p=0.0655)$. 